\title{
Mimosa L. (Fabaceae) em Cachoeira dos Índios, Paraíba, Brasil
}

\author{
Emanuel Evaristo de Sousa ${ }^{\mathrm{a}}$, Rubens Teixeira de Queiroz ${ }^{\mathrm{b}}$, Maria do Socorro Pereira ${ }^{\mathrm{a}^{*} \bullet}$ \\ a Universidade Federal de Campina Grande, Cajazeiras, 58900-000, Paraíba, Brasil. *emanuel09692@gmail.com \\ b Programa de Pós-Graduação em Mestrado Profissional em Ensino de Biologia, Universidade Federal da Paraíba, João Pessoa, \\ 58051-900, Paraíba, Brasil.
}

Recebido: 7 abril 2020 / Aceito: 12 junho 2020 / Publicado online: 27 janeiro 2021

\begin{abstract}
Resumo
Mimosa é um gênero Neotropical, com grande representatividade na Caatinga, domínio onde está inserido o município de Cachoeira dos Índios. $\mathrm{Na}$ área de estudo, os representantes do gênero foram coletados no período de dezembro/2018 a janeiro/2020. Foram levantadas nove espécies de Mimosa: (M. arenosa (Willd.) Poir., M. camporum Benth., M. candollei R. Grether, M. debilis Humb. \& Bonpl. ex Willd., M. invisa Mart. ex Colla, M. paraibana Barneby, M. sensitiva L., M. tenuiflora (Willd.) Poir. e M. ursina Mart.), destas, M. camporum, M. invisa e M. ursina são novos registros para o estado e M. paraibana, um táxon endêmico do Nordeste brasileiro. Sendo assim, evidencia-se a relevância deste ambiente, pois além de ampliar a distribuição geográfica do gênero na Paraíba, traz contribuições taxonômicas do grupo para flora da região.
\end{abstract}

Palavras-chave: Caatinga, Caesalpinioideae sensu lato, Flora, Leguminosae.

\section{Mimosa L. (Fabaceae) in Cachoeira dos Índios, Paraíba, Brazil}

\begin{abstract}
Mimosa is a Neotropical genus with great representation in the Caatinga, a domain where the municipality of Cachoeira dos Índios is located. In the study area, representatives of the genus were collected from December/2018 to January/2020. Nine species of Mimosa were identified: (M. arenosa (Willd.) Poir., M. camporum Benth., M. candollei R. Grether, M. debilis Humb. \& Bonpl. ex Willd., M. invisa Mart. ex Colla, M. paraibana Barneby, M. sensitiva L., M. tenuiflora (Willd.) Poir. e M. ursina Mart.). Out of these, M. camporum, M. invisa, M. sensitiva and M. ursina are new records for the state and M. paraibana is an endemic taxon in Northeast Brazil. Thus, the relevance of this environment is evidenced, because in addition to expanding the geographic distribution of the genus in Paraíba, it brings taxonomic contributions from the group to the region's flora.
\end{abstract}

Keywords: Caatinga, Caesalpinioideae sensu lato, Flora, Leguminosae.

\section{Introdução}

Mimosa L. abrange cerca de 540 espécies, com maioria de distribuição Neotropical e 40 nativas do Velho Mundo. O grupo ocorre em vários tipos de habitats, especialmente em áreas mais abertas de florestas, savanas, campos, caatingas, desertos ou antropizadas. Os principais centros de diversidade são México, Paraguai, Uruguai, Argentina. No Brasil, são encontradas 368 espécies, sendo 268 endêmicas do país. Para o Nordeste, são relatadas 88 espécies, das quais 14 já foram apontadas para o estado da Paraíba. É o gênero de Fabaceae mais representativo na Caatinga com 57 táxons registrados até o momento (Barneby, 1991; Queiroz, 2009; Simon et al., 2011; Santos-Silva; Simon \& Tozzi, 2015; Flora do Brasil em construção, 2020).

O gênero diferencia-se dos demais da família por apresentar frutos do tipo craspédio, com margens persistentes constituindo o replo, valvas segmentadas em artículos monospérmicos ou menos frequentemente inteiras, flores isostêmones ou diplostêmones, anteras sem glândulas apicais e ausência de nectários foliares, exceto em alguns membros de Mimosa sect. Mimadenia (Queiroz, 2009). Na classificação infragenérica, proposta por Barneby (1991), Mimosa constitui cinco seções: $M$. sect. Mimadenia Barneby, $M$. sect. Batocaulon, M. sect. Calothamnos, M. sect. Habbasia e M. sect. Mimosa.

O grupo é ecologicamente importante nas regiões semiáridas, tanto por seus táxons de crescimento rápido e alta capacidade de regeneração, que contribuem para a colonização e recuperação de ambientes degradados, quanto por fornecerem recursos florais, como pólen e néctar, que servem de alimento para vários tipos de insetos, especialmente abelhas (Maia-Silva, Silva, Hrncir, Queiroz \& Imperatriz-Fonseca, 2012; Döhler \& Pina, 2017).

Apesar de sua importância, trabalhos que abordam especificamente Mimosa em áreas de Caatinga, como os de Silva \& Sales (2008) e Dourado, Conceição e Santos-Silva (2013), ainda são escassos, sendo o gênero citado principalmente em levantamentos florísticos regionais. 
Dentre estes, podem ser citados os estudos de Queiroz (2009), na Caatinga, Matos, Melo e Santos-Silva (2019), no Pernambuco, Silva \& Melo (2013), Ferreira, Trovão \& Melo (2015), Rodrigues (2018) e Farias, Lacerda, Gomes, Barbosa \& Dornelas (2017), na Paraíba. Em virtude disto, este estudo foi proposto, para catalogar e caracterizar as espécies do gênero ocorrentes no município de Cachoeira dos Î́ndios, Paraíba, Brasil, visando assim, o conhecimento da flora em ambientes nunca investigados, que apesar das constantes ações antrópicas, ainda guardam remanescentes de vegetação nativa, que podem trazer novas informações sobre a distribuição, diversidade e riqueza destes táxons no estado.

\section{Material e Métodos}

\section{Área de Estudo}

O município de Cachoeira dos Índios está situado no extremo oeste do estado da Paraíba (38 $48^{\circ} 26^{\prime \prime}$ de longitude oeste e $06^{\circ} 55^{\prime} 37^{\prime \prime}$ de latitude sul), compreendendo $193,6 \mathrm{~km}^{2}$ de extensão (Instituto Brasileiro de Geografia e Estatística [IBGE], 2018), os solos são do tipo Argissolos, podendo haver porções restritas de Latossolos e Neossolos (Embrapa Solos, 2018).

O clima é Semiárido, com temperaturas variando entre 23 e $30^{\circ} \mathrm{C}$ e precipitação média de $913,2 \mathrm{~mm} /$ ano. O município se insere na Bacia Hidrográfica do Rio Piranhas, Sub-Bacia do Rio do Peixe, com cursos hídricos intermitentes, além de açudes. As fitofisionomias são típicas de Caatinga, predominando formações arbustivo-arbóreas abertas, de pequeno a médio porte.

As coletas foram realizadas de dezembro/2018 a janeiro/2020, em 10 pontos de coletas (Tabela 1).

Tabela 1. Localização dos pontos de coleta de material botanico em Cachoeira dos Índios, Paraíba, Brasil.

\begin{tabular}{|c|c|c|}
\hline \multirow{2}{*}{ Estação } & \multicolumn{2}{|c|}{ Coordenadas } \\
\hline & Latitude & Longitude \\
\hline P1 - Sítio Redondo & $6^{\circ} 56^{\prime} 09.42^{\prime \prime S}$ & $38^{\circ} 39^{\prime} 18.03 ” O$ \\
\hline P1 - Sítio Redondo & $6^{\circ} 56^{\prime} 46.56^{\prime \prime} \mathrm{S}$ & $38^{\circ} 38^{\prime} 51.71$ 'O \\
\hline P2 - Sítio Baixa Grande & $7^{\circ} 01 ' 26.07^{\prime \prime S} \mathrm{~S}$ & $38^{\circ} 40^{\prime} 46.48^{\prime \prime} \mathrm{O}$ \\
\hline $\begin{array}{l}\text { P3 - Distrito de São José } \\
\text { de Marimbas }\end{array}$ & $6^{\circ} 59^{\prime} 06.08^{\prime \prime} \mathrm{S}$ & $38^{\circ} 39^{\prime} 36.19^{\prime \prime} \mathrm{O}$ \\
\hline P4 - Distrito de Tambor & $6^{\circ} 54^{\prime} 48.46^{\prime \prime} \mathrm{S}$ & $38^{\circ} 42^{\prime} 06.71^{\prime \prime} \mathrm{O}$ \\
\hline P5 - Serrote do Quati & $6^{\circ} 59^{\prime} 51.86^{\prime \prime} \mathrm{S}$ & $38^{\circ} 40^{\prime} 08.92^{\prime \prime} \mathrm{O}$ \\
\hline P6 - Sítio Angical & $6^{\circ} 53^{\prime} 44.47^{\prime \prime} \mathrm{S}$ & $38^{\circ} 39^{\prime} 28.15^{\prime \prime} \mathrm{O}$ \\
\hline P7 - Sítio Lagoa do Mato & $6^{\circ} 58^{\prime} 33.73 ” \mathrm{~S}$ & $38^{\circ} 39^{\prime} 21.04^{\prime \prime} \mathrm{O}$ \\
\hline P8 - Sítio Larges & $6^{\circ} 53^{\prime} 56.43^{\prime \prime} \mathrm{S}$ & $38^{\circ} 40^{\prime} 00.93^{\prime \prime} \mathrm{O}$ \\
\hline P9 - Sítio Pedras Pretas & $7^{\circ} 01^{\prime} 01.03 ” \mathrm{~S}$ & $38^{\circ} 40^{\prime} 10.15^{\prime \prime} \mathrm{O}$ \\
\hline P10 - Sítio São Joaquim & $6^{\circ} 56^{\prime} 09.42 ” S$ & $38^{\circ} 39^{\prime} 18.03 ” O$ \\
\hline
\end{tabular}

\section{Estudo Taxonômico}

As amostras coletadas foram herborizadas conforme a metodologia de Gadelha-Neto et al. (2013), para depósito no Herbário Lauro Pires Xavier (JPB), cadastrado na rede do SpeciesLink Network. As descrições morfológicas foram feitas no Laboratório de Botânica da Universidade Federal de Campina Grande, Campus Cajazeiras, com base nos espécimes exclusivamente da área de estudo, seguindo a circunscrição adotada pelo The Legume Phylogheny Working Group (LPWG, 2017). A morfologia foi baseada em Vidal e Vidal (2003), Gonçalves e Lorenzi (2011), Souza, Flores e Lorenzi (2013).

As identificações seguem Barneby (1991), Silva e Sales (2008), Queiroz (2009), Dourado et al., (2013), Silva e Melo (2013), Santos-Silva et al., (2015), Tozzi et al. (2016), Mattos et al. (2018), além de análise das coleções-tipo em herbários virtuais (INCT-HVFF, SpeciesLink Network, REFLORA-JBRJ) e por fim, confirmadas por especialistas. As abreviaturas dos nomes dos autores estão de acordo com a Flora do Brasil 2020 (Flora do Brasil em construção, 2020).

A distribuição geográfica das espécies segue o disposto na Flora do Brasil 2020 e/ou com demais referenciais teóricos consultados (Burkart, 1979; Barneby, 1991; Queiroz, 2009; BFG, 2015; Santos-Silva et al., 2015; Tozzi et al., 2016; Mattos et al., 2018). O mapa de localização da área de estudo foi confeccionado a partir do programa QGis 2.18.28. Os percentuais dos hábitos foram obtidos através de cálculos simples de regra de três.

\section{Resultados e Discussão}

Foram encontradas nove espécies de Mimosa (Mimosa arenosa (Willd.) Poir., M. camporum Benth., M. candollei R. Grether, M. debilis Humb. \& Bonpl. ex Willd., M. invisa Mart. ex Colla, M. paraibana Barneby, M. sensitiva L., $M$. tenuiflora (Willd.) Poir. e M. ursina Mart.), o que corresponde a $64 \%$ dos táxons do gênero já constatados na Paraíba, distribuídas nas seguintes seções: Mimosa sect. Batocaulon (Mimosa arenosa (Willd.) Poir., M. candollei R. Grether, M. invisa Mart. ex Colla, M. paraibana Barneby e M. tenuiflora (Willd.) Poir.), Mimosa sect. Mimosa (Mimosa debilis Humb. \& Bonpl. ex Willd., M. sensitiva L. e M. ursina Mart.) e Mimosa sect. Habbasia (M. camporum Benth.).

Destas, predominam espécies subarbustivas $(44,4 \%)$, seguidas por arbustivas $(33,3 \%)$, lianas $(22,2 \%)$ e arvoretas $(11,1 \%)$. Mimosa camporum, $M$. invisa e $M$. ursina são aqui apontadas como novos registros para o estado da Paraíba. Mimosa paraibana é uma espécie endêmica do Nordeste brasileiro, ocorrendo, principalmente, na cobertura vegetal nativa de Caatinga (Queiroz, 2009).

Na Bahia, Dourado et al., (2013), apontaram 11 espécies para a Área de Preservação Ambiental Serra Branca/Raso da Catarina. Já no Pernambuco, Silva \& Sales (2008), registraram a ocorrência de 11 táxons para a microrregião do Vale do Ipanema. Em ambos, Mimosa sect. Batocaulon destaca-se como a seção mais representativa, o que está em consonância com os resultados constatados no presente estudo.

Dentre os levantamentos florísticos realizados em regiões de Caatinga Paraibana que incluem Mimosa (Silva \& Melo (2013); Ferreira et al. (2015); Farias et al. (2017) e Rodrigues (2018)), o primeiro foi o que relatou o maior número de representantes do gênero (5 spp.).

\section{Mimosa L., Sp. Pl. 1: 516.1753}

Arvoretas, arbustos, lianas ou subarbustos. Ramos 
cilíndricos, tetrangulares ou costados, armados, acúleos retos ou retrorsos, infranodais, internodais ou seriados. Tricomas simples, glandulares ou setosos. Folhas palmadas, bipinadas, paripinadas, uni-multijuga; estípulas persistentes ou caducas; pecíolos cilíndricos ou quadrangulares; movimentos tigmonásticos presentes ou ausentes; espículas interpinais presentes ou ausentes; parafilídios presentes. Inflorescências espigas ou glomérulos, solitárias ou 2-3-fasciculadas, axilares ou em pseudorracemos terminais. Flores sésseis; cálice campanulado ou tubuloso, 4-5-lobado; corola campanulada ou tubulosa, 4-5-mera, branca ou rósea; androceu isostêmone ou diplostêmone, filetes brancos ou róseos, anteras oblongas ou ovoides, rimosas; ovário oblongo, séssil ou subséssil, estilete filiforme. Fruto craspédio, séssil ou estipitado, planocompresso, plano-corrugado ou quadrangular, armado ou inerme; replo reto ou sinuoso. Sementes elipsoides, oblongas ou ovoides, castanhas, cinzas, marrons ou pretas.

Chave de identificação das espécies de Mimosa em Cachoeira dos Índios, Paraíba, Brasil

1. Folhas palmadas, raque ausente, 1 par de pinas 2

2. Foliólulos 4-5 pares, oblongos. 9. Mimosa ursina

2'. Foliólulos 2 pares, obovado ou falcado . 3

3. Liana, foliólulos falcados, estípulas $3.4-5.5 \mathrm{~mm}$ compr

7. Mimosa sensitiva

3'. Subarbusto decumbente, foliólulos obovados, estípulas 3.4-5.5 mm compr. 4. Mimosa debilis

1'. Folhas pinadas, raque presente, 2 ou mais pares de pina. 4

4. Liana 5. Mimosa invisa

4' Subarbusto, arbusto ou arvoreta..... 5

5. Subarbusto com ramos híspidos ou pilosos... 6

6. Ramos cilíndricos, híspidos, acúleos retos, craspédio inerme. 2. Mimosa camporum

6'. Ramos tetrangulares, pilosos, acúleos retrorsos, craspédio armado 3. Mimosa candollei

5'. Arbusto ou arvoreta com ramos tomentosos ou pubescentes 6

7. Ramos estriados, inflorescência glomérulo, flores róseas, craspédio $2-3 \mathrm{~cm}$ larg 6. Mimosa paraibana

7'. Ramos lisos, inflorescência espiga, flores alvas, craspédio $0.4-0.7 \mathrm{~mm}$ larg 8

8. Ramos verdes ou cinzas, folha sem pontuações glandulares na face abaxial, craspédio planocompresso.

1. Mimosa arenosa

8'. Ramos marrons ou vináceos, folha com pontuações glandulares na face abaxial, craspédio planocorrugado.

8. Mimosa tenuiflora

1. Mimosa arenosa (Willd.) Poir., Encycl. Suppl. 1: 66.1810. (Figura 2A-B)

Arbusto 2,5-4,0 m alt. Ramos verdes ou cinzas, cilíndricos, lisos, aculeados, tomentosos, lenticelados, tricomas simples e glandulares. Acúleos 2,0-4,0 $\mathrm{mm}$ comp., internodais, retrorsos. Estípulas 2,3-4,7 $\times 0,2-0,5 \mathrm{~mm}$, lineares a estreitamente triangulares, velutinas a pubescentes, tricomas simples. Folhas pinadas, $4-8$ pares de pinas; pecíolos $0,9-1,7$ cm comp, cilíndrico, sulcado, tomentoso, tricomas simples e glandulares; raque 1,8-10 × 2-4,7 cm, cilíndrica, sulcada, tomentosa, tricomas simples e glandulares; movimentos tigmonásticos ausentes; espículas interpinais triangulares; parafilídios cônicos; pinas 1,0-4,0 × 0,3-0,6 cm, oblongas; foliólulos 2,0-5,0 × 1,0 mm, oblongos, ápice mucronado, base oblíqua, margem inteira, ambas as faces pubescentes, sem pontuações glandulares na face abaxial, nervação acródroma. Espigas 2,5-6,5 × 0,7-1,8 cm, cilíndricas, axilares, solitárias, 2-3-fasciculadas ou agrupadas em pseudorracemos terminais; pedúnculos 4,0-9,0 $\mathrm{mm}$ comp., cilíndricos, tomentosos, tricomas simples e glandulares; brácteas 1,3-1,4 mm comp., lanceoladas, verdes, glabras. Flores $0,4-1,0 \times 0,1-0,4 \mathrm{~cm}$, subsésseis; cálice $0,5-0,6 \times 0,3-0,5 \mathrm{~mm}$, campanulado, branco, glabro; corola 2,0-3,0 × 1,0-2,0 mm, tetrâmera, campanulada, lacínias eretas, branca, glabra; androceu diplostêmone, filetes 3,8-7,9 mm comp., livres, brancos, anteras oblongas a ovoides, amarelas; ovário ca. 1,0 mm comp., curtamente estipitado, glabro, estilete ca. 7,0 mm comp. glabro. Craspédios 3,0-6,2 ×0,4-0,5 cm, lineares, $3-$ 8 articulados, marrons, estipitados, cartáceos, planocompressos, ápice mucronado, base atenuada, glabros; estípite 5,0-10 mm comp.; artículos quadrangulares; replo reto, glabro. Sementes 3,4-3,6 × 2,8-2,9 mm, 3-8, ovoides, marrom-claras.

Material examinado: Sítio Baixa Grande, 04 maio 2019, fl., E. E. Sousa 99 (JPB); 02 jun 2019, fr., E. E. Sousa 107 (JPB); 05 ago 2019, fr., E. E. Sousa 126 (JPB).

Distribuição geográfica: Pode ser encontrada nas áreas secas de Porto Rico, Venezuela e no Brasil. Neste último, é referida em toda região Nordeste, estendendo-se até Minas Gerais e cultivada no estado de São Paulo. Registrada na Caatinga como espécie invasora de áreas antropizadas, ocorrendo em solos arenosos com ou sem afloramentos rochosos e em áreas susceptíveis a inundações (Queiroz, 2009; Santos-Silva et al., 2015; Flora do Brasil em construção, 2020). Coletada na área de estudo em ambientes mais abertos e próximo a açudes. Nos locais onde foi encontrada, o extrato mais desenvolvido era o arbustivoarbóreo, onde a espécie figurava como uma das mais frequentes, juntamente com $M$. tenuiflora, Piptadenia 
stipulacea (Benth.) Ducke (Fabaceae), Combretum leprosum Mart. (Combretaceae), Croton sonderianus Muell. Arg. (Euphorbiaceae), Mesosphaerum suaveolens (L.) Kuntze (Lamiaceae) e Ziziphus joazeiro Mart. (Rhamnaceae). Abelhas foram visualizadas polinizando a espécie.

Notas taxonômicas: Entre as espécies da área a mais próxima de $M$. arenosa é $M$. tenuiflora, pois ambas compartilham características como indumento com tricomas simples e glandulares, folhas com múltiplos pares de pinas e inflorescência em espiga com flores alvas. Porém, $M$. arenosa tem ramos verdes a cinzas, lenticelados, acúleos retrorsos, folíolos sem pontuações glandulares na face abaxial e craspédio plano-compresso, não inflado na altura da semente, glabro ( $v s$. ramos marrons a vináceos, sem lenticelas, acúleos retos, folíolos com pontuações glandulares na face abaxial e craspédio plano-corrugado, inflado na altura da semente, puberulento em $M$. tenuiflora). Floresce em maio e frutifica de junho a agosto. Conhecida popularmente como calumbi.

2. Mimosa camporum Benth. J. Bot. (Hooker) 2(11): 130. 1840. (Figura 2C-D)

Subarbustos eretos, 0,5-1,0 m alt. Ramos cilíndricos, verdes, aculeados, híspidos, tricomas simples. Acúleos 1,0-3,0 mm comp., longo-subulados, distribuídos esparsamente pelos ramos. Estípulas $0,5-1,1 \times 0,1 \mathrm{~cm}$, lanceoladas, verdes, margem ciliada, tricomas simples. Folhas pinadas, 2-6 pares de pinas; pecíolos 0,6-2,0 cm comp., cilíndricos, aculeados, híspidos, tricomas simples; raque 0,6-4,5 cm comp., cilíndrica, aculeada, híspida, tricomas simples; espículas interpinais triangulares; parafilídios cônicos; movimentos tigmonásticos presentes; pinas 1,1-4,7 × 0,3-0,6 cm, oblongas; foliólulos $0,2-0,7 \times 0,1-0,2 \mathrm{~cm}$, sésseis, oblongos, membranáceos, base oblíqua, margem longamente ciliada, ápice mucronado, glabros em ambas as faces, tricomas simples, nervação actinódroma. Glomérulos 0,3-0,8 cm diâm., globosos, solitários, axilares; pedúnculos 0,4-0,8 cm comp., cilíndricos, híspidos, tricomas simples; brácteas 2,0-3,0 mm comp., lanceoladas, verdes, margens ciliadas. Flores 5,0-6,0 × 1,0 $\mathrm{mm}$, sésseis; cálice $0,5 \times 0,5 \mathrm{~mm}$, campanulado, branco, glabro; corola 1,5-2,0 × 0,8-1,0 mm, tetrâmera, campanulada, lacínias eretas, branca, glabra; androceu diplostêmone, filetes 3,0-4,0 mm comp., livres, róseos; anteras oblongas, amarelas; ovário ca. 0,5 mm comp., oblongo, denso-seríceo, tricomas simples, estilete 4,0-5,0 mm comp., seríceo, tricomas simples. Craspédios 0,9-1,2 × 0,4-0,5 cm, oblongos, verdes, sésseis, cartáceos, 2-3 articulados, ápice arredondado, base aguda, híspidos, tricomas simples; artículos quadrangulares; replo reto, adpresso, híspido, tricomas simples. Sementes não observadas.

Material examinado: Sítio Baixa Grande, 07 abr 2019, fl., fr., E. E. Sousa 78 (JPB).

Distribuição geográfica: Mimosa camporum ocorre na Argentina, Bolívia, Paraguai e Brasil. No Brasil, é citada para as regiões Norte, Nordeste e Centro-Oeste. Encontrada em áreas de vegetação de transição, ou antropizadas (Barneby, 1991; BFG, 2015; Mattos et al., 2018, Flora do Brasil em construção, 2020). Aqui, é apontada como novo registro para a Paraíba, coletada em Cachoeira dos Índios, crescendo em áreas mais abertas, onde predominava o extrato herbáceo. A espécie estava associada a outros táxons de Fabaceae (M. candollei, $M$. debilis, Stylosanthes humilis Kunth.), de Lamiaceae ( $M$. suaveolens) e Poaceae. Visitantes florais não foram observados.

Notas taxonômicas: Mimosa camporum pode ser distinguida das demais na área de estudo pelos acúleos longo-subulados, esparsos nos ramos, sendo estes híspidos, gineceu denso-seríceo e craspédios com replo adpresso, híspido. Compartilha o hábito subarbustivo com Mimosa ursina, mas são facilmente distintas pela presença de 1 par de folíolos em M. ursina (vs. 3-7 pares em M. camporum). Observada em floração e frutificação em abril.

\section{Mimosa candollei R. Grether, Novon 10: 34. 2000.} (Figura 2E-F)

Subarbusto escandente ou prostrado, ca. $1 \mathrm{~m}$ alt. Ramos tetragonais, verdes, costados, pilosos, aculeados, tricomas simples e glandulares. Acúleos 0,4-2,1 mm comp., retrorsos, seriados. Estípulas 2,7-3,7 × 0,1-0,2 mm, lanceoladas a aciculadas, verdes, pilosas, tricomas simples. Folhas pinadas, (1)-2-3 pares de pinas; pecíolos 2,2-5,4 cm comp., tetrangulares, aculeados, pilosos, tricomas simples e glandulares; raque $8,5-18,5 \mathrm{~mm}$ comp., tetrangular, aculeada, pilosa, tricomas simples e glandulares; espículas interpinais filiformes, parafilídios ovais; pinas 2,3-5,5 $\times 0,8-$ 2,4 cm, oblongas; foliólulos 13-19 pares, 2,7-14 × 1,3-3,0 $\mathrm{mm}$, oblongos, membranáceos, ápice mucronado, base oblíqua, margem ciliada, face adaxial glabra, face abaxial estrigosa no primeiro par de folíolos e puberulenta nos demais, nervação hifódroma, tricomas simples. Glomérulos 2,4-7,1 mm diâm., globosos, solitários ou 2-fasciculados, axilares; pedúnculos ca. 1,5 $\mathrm{mm}$ comp., cilíndricos, pubescentes; brácteas 1,8-2,7 ×0,2 mm, lanceoladas, verdes, pubescentes. Flores 2,0-3,7 × 1,1-2,0 mm, sésseis; cálice 0,4 $\times 0,2 \mathrm{~mm}$, campanulado, rosa, glabro; corola 0,8 $\times 0,9-1,2$ $\mathrm{mm}$, tetrâmera ou pentâmera, campanulada, lacínias eretas, rosa, glabra; androceu diplostêmone, filetes 2,7-4,7 mm compr., livres, róseos, anteras oblongas, amarelas; ovário ca. 0,7 mm comp., séssil, oblongo, glabro, estilete ca. 0,4 mm comp., glabro. Craspédios 8,0-11,5 × 0,2-0,4 cm, lineares, tetragonais, planos, pardos, cartáceos, estriados, não articulados, aculeados, puberulentos, ápice estreitamente atenuado formando um rostro, base aguda, tricomas glandulares; replo reto, espesso, aculeado, puberulento, tricomas glandulares. Sementes 3,0-4,8 $\times$ 2,1-2,8 mm, oblongas a elipsoides, pretas.

Material examinado: Sítio Baixa Grande, 16 mar 2019, fl., fr., E. E. Sousa 65 (JPB); 07 abr 2019, fl., fr., E. E. Sousa 79 (JPB); Sítio Redondo, 05 ago 2019, fl., fr., E. E. Sousa 132, 133 (JPB).

Distribuição geográfica: Mimosa candollei apresenta ampla distribuição pelo continente Americano, ocorrendo do sul dos Estados Unidos até a Argentina. No Brasil, tem registros no Norte, Nordeste, Centro-oeste, Sudeste e Sul. Encontrada em áreas de Caatinga, Cerrado, Mata Ciliar, Floresta Estacional Semidecidual e Restinga, crescendo em solos úmidos e campos arenosos, além de ambientes antropizados (Burkart, 1979; Tozzi et al., 2016; Flora do Brasil em construção, 2020). Coletada na área de estudo em serrotes ou próximo a açudes. Nos locais onde foi encontrada, predominava o extrato herbáceo, com apenas alguns arbustos 
esparsos, onde a espécie encontrava-se associada a representantes do mesmo gênero e da mesma família (Desmodium glabrum (Mill.) DC., Mimosa camporum, M. debilis, M. tenuiflora, Rynchosia minima (L.) DC., S. humilis), assim como de Combretaceae (C. leprosum), Lamiaceae $(M$. suaveolens) e Poaceae. Visitantes florais não foram visualizados.

Notas taxonômicas: Mimosa candollei pode ser diagnosticada pelo hábito subarbustivo prostrado ou escandente, ramos tetragonais com acúleos seriados, flores com corolas em sua maioria pentâmeras, craspédios lineares, tetragonais em seção transversal, não articulados, ápice estreitamente atenuado formando um rostro e replo largo, aculeado. Facilmente reconhecida das demais pelos frutos lineares. Ocorre em ambientes arenosos. Floresce e frutifica de março a agosto. Popularmente conhecida como malissa.

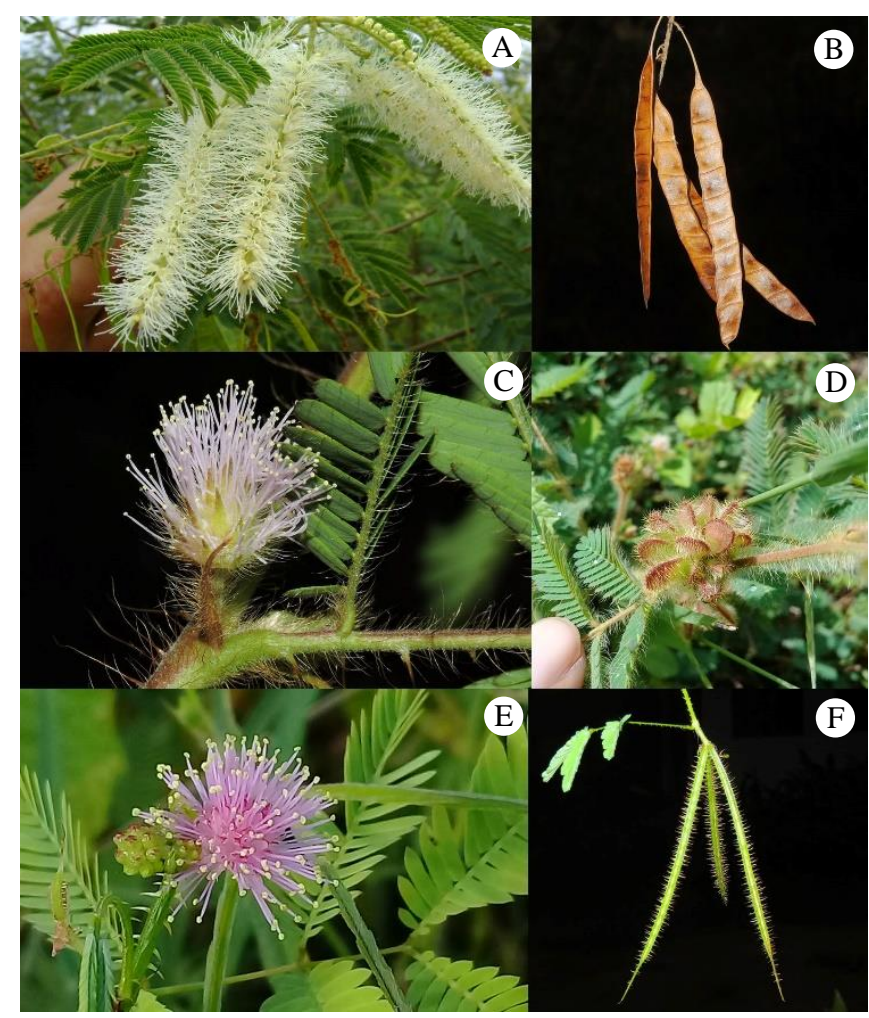

Figura 2. A-B. Mimosa arenosa A. Espigas; B. Craspédios; C-D. Mimosa camporum C. Glomérulo; D. Craspédios; E-F. Mimosa candollei E. Glomérulo; F. Craspédios.

4. Mimosa debilis Humb. \& Bonpl. ex Willd. Sp. pl. 4(2): 1029. 1806. (Figura 3A-B)

Subarbusto decumbente, ca. $30-50 \mathrm{~cm}$ alt. Ramos cilíndricos, verdes, híspidos, aculeados. Acúleos ca. 0,2 mm comp., retrorsos, com base larga, internodais. Estípulas 1,4-1,9 $\times$ 0,2-0,4 mm, lanceoladas, estriadas, verdes, híspidas, margens ciliadas. Folhas palmadas, 1 par de pinas; pecíolos 1,4-5,5 cm comp., cilíndricos, híspidos; raque ausente, movimentos tigmonásticos presentes, espículas interpinais ausentes, parafilídios lineares a lanceolados; pinas 2,2-4,0 $\times$ 0,8-3,4 cm; foliólulos 2 pares, 0,5-3,3 × 0,2-1,6 cm, o par basal com um de seus foliólulos atrofiado, membranáceos, obovados, ápice acuminado, margem estrigosa, base oblíqua, face adaxial glabra, face abaxial estrigosa, nervação broquidódroma, tricomas simples. Glomérulos $0,2-0,4 \mathrm{~cm}$ diâm., globosos, solitários ou 2-fasciculados, axilares; pedúnculos 0,5-1,1 cm comp., cilíndricos, glabros; brácteas 1,8-2,0 mm comp., lineares, verdes, margens ciliadas. Flores 2,0-4,0 × 0,5-0,8 mm, sésseis; cálice 0,5 × 0,4 mm, tubuloso, irregularmente denteado, branco, glabro; corola $1,0 \times 0,7 \mathrm{~mm}$, tubulosa, pentâmera ou tetrâmera, lacínios eretos a encurvados, branca, glabra; androceu isostêmone, filetes 2,0-3,0 mm comp., livres, róseos, anteras oblongas, brancas; ovário ca. 1,0 mm comp., oblongo, séssil, glabro, estilete 2,0-3,0 mm comp., glabro. Craspédios 1,4-1,9 $\times$ 0,2-0,4 cm, oblongos, verdes, plano-compressos, cartáceos, 2-3 articulados, ápice mucronado, base arredondada, híspidos, artículos quadrangulares, tricomas simples; replo reto, híspido, tricomas simples. Sementes não observadas.

Material examinado: Serra do Quati, 26 fev 2019, fl., E. E. Sousa 43, 44, 45, 46, 47 (JPB). Sítio Baixa Grande, 07 abr 2019, fl., fr., E. E. Sousa 81 (JPB).

Distribuição Geográfica: A espécie pode ser encontrada na América Tropical, ocorrendo na Argentina, Bolívia, Colômbia, Venezuela, Paraguai e Brasil. No Brasil, tem ampla distribuição com registros em todas as regiões do país e está associada ao Cerrado, Capoeira, Mata Ciliar e ambientes antrópicos, crescendo em solos arenosos ou pedregosos, em altitudes de até 600 metros (Tozzi et al., 2016; Flora do Brasil em construção, 2020). Coletada em Cachoeira dos Índios em região serrana e áreas abertas, com predominância do extrato herbáceo, sendo uma espécie frequente, associada a outros representantes de Fabaceae (Indigofera blanchetiana Benth., Mimosa camporum, $M$. ursina, S. humilis) e também de Lamiaceae e Poaceae. Não foram observados visitantes florais.

Notas taxonômicas: Mimosa debilis faz parte de um complexo de espécies crípticas (Tozzi et al., 2016), no qual também está inserida Mimosa sensitiva, outro táxon observado em Cachoeira dos Índios. Essas duas espécies compartilham as folhas com apenas um par de pinas. Entretanto, $M$. debilis apresenta hábito subarbustivo decumbente e foliólulos obovados (vs. hábito lianescente e folíolos falcados em $M$. sensitiva). Floresce de fevereiro a abril e frutifica em abril.

5. Mimosa invisa Mart. ex Colla, Herb. Pedem 2: 255. 1834. (Figura 3C-D)

Lianas, 2,5-3,0 $\mathrm{m}$ alt. Ramos verdes, costados, aculeados, tomentosos, tricomas simples e glandulares. Acúleos ca. 0,1 cm comp., retrorsos, seriados. Estípulas 0,2$0,3 \times 0,1 \mathrm{~cm}$, subuladas, verdes, tomentosas, tricomas simples. Folhas pinadas, 3-10 pares de pinas; pecíolos 2,4$3,8 \mathrm{~cm}$ comp., cilíndricos, aculeados; raque 2,0-5,2 cm comp., cilíndrica, aculeada; movimentos tigmonásticos presentes; espículas interpinais lanceoladas a triangulares; parafilídios ovais; pinas 1,3-4,0 × 0,2-0,4 cm, oblongas; foliólulos 0,2-0,4 ×0,1 cm, sésseis, oblongos, cartáceos, ápice arredondado a obtuso, base oblíqua, margem inteira, tomentosos em ambas as faces, nervação hifódroma. Espigas 4,6-6,4 × 0,2-0,5 cm, cilíndricas, solitárias ou 2fasciculadas, axilares ou dispostas em pseudorracemos terminais; pedúnculos 1,0-1,8 cm comp., cilíndricos, aculeados, tomentosos, tricomas simples; brácteas ca. 0,5 
mm comp., oblanceoladas, verdes, margens ciliadas, tricomas simples. Flores 4,0-6,0 × 1,0 mm, sésseis; cálice 0,5 ×0,5 mm, tubuloso, rosa, puberulento, tricomas simples; corola $0,8-1,0 \times$ 0,2-1,0 mm, campanulada, tetrâmera a pentâmera, rosa, vilosa, lacínias eretas, tricomas simples; androceu diplostêmone, filetes 4,0-5,0 mm comp., livres, róseos, anteras oblongas, amarelas; ovário ca. 0,1 mm comp., oblongo, curto-estipitado, tomentoso, tricomas simples. Craspédios 1,4-7,0 $\times$ 0,6-1,0 $\mathrm{cm}$, oblongos, 3-12 articulados, marrons, estipitados, planocompressos, cartáceos, ápice mucronado, base arredondada a cuneada, vilosos, tricomas simples; estípite 2,0-4,0 mm comp.; artículos quadrangulares a retangulares; replo reto, viloso, com acúleos esparsos, tricomas simples. Sementes 3,0-5,0 × 2,03,0 $\mathrm{mm}$, ovais a oblongas, marrons.

Material examinado: Sítio Baixa Grande, 21 abr 2019, fl., E. E. Sousa 87, 88 (JPB); Serra do Quati, 17 ago 2019, fr., E. E. Sousa 140 (JPB).

Distribuição geográfica: Mimosa invisa distribui-se na Colômbia, Venezuela, Paraguai e Brasil. No Brasil, é encontrada nas regiões Norte, Nordeste e Sudeste, associada a diversos tipos de ambientes, como Caatinga, Cerrado, Floresta Ombrófila, Floresta Estacional Decidual, Carrasco, Campo Rupestre, Campo de Altitude, Mata Ciliar e Capoeira, assim como em áreas antropizadas (Tozzi et al., 2016; Flora do Brasil em construção, 2020). Em Cachoeira dos Índios foi coletada em áreas serranas, sendo uma nova ocorrência para a Paraíba. Verificou-se que, nos ambientes de coleta, o extrato predominante era o arbustivo-arbóreo, tendo $M$. invisa como uma das espécies mais frequentes, associada a táxons da mesma família (Bauhinia pulchella Benth., Pityrocarpa moniliformis (Benth.) Luckow \& R. W. Jobs., Senna trachypus (Mart. ex Benth.) H. S. Irwin \& Barneby, de Combretaceae ( $C$. leprosum), Euphorbiaceae ( $C$. sonderianus) e Lamiaceae $(M$. suaveolens). Também foram vistas trepadeiras herbáceas da família Convolvulaceae. Foi visitada por abelhas durante sua floração.

Notas taxonômicas: Mimosa invisa compartilha com $M$. arenosa e $M$. tenuiflora folhas multijugas e inflorescência espiciforme. No entanto, $M$. invisa tem hábito lianescente e flores róseas ( $v s$. hábito arbustivo e flores alvas em $M$. arenosa e $M$. tenuiflora). Diferencia-se das demais espécies da família em Cachoeira dos Índios pelo hábito lianescente, acúleos seriados dispostos sobre as costelas dos ramos, pecíolos, raque foliar e pedúnculo, espigas com flores róseas e craspédios com replo provido de acúleos esparsos. Observada em floração em abril e frutificação em agosto.

\section{Mimosa paraibana Barneby, Mem. New York Bot. Gard.} 65: 171. 1991. (Figura 3E-F)

Arbustos 2,0-4,0 m alt. Ramos cilíndricos, estriados, verdes, aculeados, tomentosos, tricomas simples e glandulares. Acúleos ca. 1,0 mm comp., retrorsos, internodais. Estípulas 0,4-0,7 $\times 0,1 \mathrm{~cm}$, lineares, verdes, tomentosas, tricomas simples. Folhas pinadas, 3-7 pares de pinas; pecíolos 1,7-3,5 cm comp., cilíndricos, aculeados, tomentosos; raque 2,2-4,8 $\mathrm{cm}$ comp., aculeada, tomentosa; movimentos tigmonásticos ausentes; espículas interpinais lanceoladas, parafilídios subulados; pinas 2,5-6,4 × 0,7-1,7 cm, oblongas; foliólulos $0,2-1,0 \times 0,1-0,4 \mathrm{~cm}$, oblongos a obovados, cartáceos, ápice arredondado a mucronado, margem inteira, ciliada, base oblíqua, ambas as faces pubescentes, nervação trinérvea. Glomérulos 1,1-1,5 cm diâm., globosos, agrupados em pseudorracemos terminais longos; pedúnculos 1,0-1,5 cm comp., cilíndricos, tomentosos, tricomas simples; brácteas ca. 1,0 mm comp., lanceoladas, verdes, pubescentes, tricomas simples. Flores 2,0-5,0 × 1,0-1,8 mm, sésseis; cálice $0,5-0,8 \times 0,5 \mathrm{~mm}$, campanulado, curtamente denticulado, róseo, glabro; corola 1,0-1,2 × 1,0 mm, campanulada, lacínias eretas a ligeiramente reflexas, tetrâmera, rósea, glabra; androceu diplostêmone, filetes 3,55,0 mm comp., livres, róseos, anteras ovoides, nigrescentes; ovário ca. 1,0 mm comp., oblongo, curto-estipitado, puberulento, estilete 3,0-4,0 mm comp., glabro. Craspédios 4,1-6,3 × 2,0-3,0 cm, oblongos, 7-9 articulados, curtoestipitados, nigrescentes, plano-compressos, cartáceos, ápice mucronado, base aguda, glabros; estípite 0,3-0,4 cm comp.; artículos retangulares; replo reto, espesso, glabro. Sementes 6,0-8,0 × 3,0-5,0 mm, oblongas, cinzas.

Material examinado: Sítio Redondo, 04 fev 2019, fl., E. E. Sousa 17 (JPB); 04 ago 2019, fr., E. E. Sousa 131 (JPB).

Distribuição geográfica: Endêmica da região Nordeste do Brasil, ocorrendo nos estados do Ceará, Maranhão, Paraíba, Pernambuco, Piauí e Rio Grande do Norte, associada a ambientes de Caatinga e Floresta Estacional Semidecidual, sobre solos arenosos e pedregosos (Barneby, 1991; Queiroz, 2009; Flora do Brasil em construção, 2020). Em Cachoeira dos Índios, foi coletada em áreas de serrote, associada principalmente a táxons arbustivo-arbóreos, como outras Fabaceae dos gêneros Mimosa, Bauhinia, Cenostigma, Chloroleucon, Lonchocarpus, Senegalia, como também representantes de outros grupos de Angiospermas típicos de Caatinga (Bromeliaceae, Cactaceae, Cochlospermaceae, Euphorbiaceae). Foram observadas abelhas visitando a espécie no período da floração.

Notas taxonômicas: Mimosa paraibana é facilmente diferenciada das demais espécies na área pelos foliólulos oblongos a obovados, relativamente largos, trinérveos, glomérulos agrupados em pseudorracemos terminais longos, anteras nigrescentes e craspédios com 2.0-3.0 cm largura, artículos e replo glabros, nigrescentes. Floresce em fevereiro e frutifica em agosto.

\section{Mimosa sensitiva L., Sp. Pl.: 518. 1753. (Figura 4A-B)}

Liana, 1,0-2,0 m alt. Ramos costados, estriados, verdes, aculeados, estrigosos a pilosos, tricomas simples. Acúleos 0,5-2,4 mm, fortemente retrorsos, seriados. Estípulas 3,4$5,5 \times 0,6-1,2 \mathrm{~mm}$, lanceoladas, verdes, pilosas, estriadas, ciliadas, tricomas simples. Folhas palmadas, 1 par de pinas; pecíolos 1,9-8,1 cm comp., cilíndricos, aculeados, estrigosos a pilosos, tricomas simples; raque ausente; movimentos tigmonásticos presentes e rápidos; espículas interpinais presentes; parafilídios subulados; pinas 3,7-6,9 × 2,6-5,0 $\mathrm{cm}$; foliólulos 2 pares, 0,7-6,0 × 0,4-2,4 cm, foliólulo interno do par basal atrofiado, falcados, membranáceos, ápice cuneado-mucronado, margem ciliada, base oblíqua, face adaxial glabra, face abaxial estrigosa, tricomas simples, nervação broquidódroma. Glomérulos 6,0-7,0 mm diâm., globosos, solitários a 3-fasciculados, axilares ou agrupados em pseudorracemos terminais curtos; pedúnculos 1,3-2,1 cm 
comp., cilíndricos, aculeados, estrigosos a pilosos, tricomas simples; brácteas 2,0-4,0 mm comp., lineares a oblanceoladas, glabras, ápice ciliado. Flores 2,4-4,0 × 0,6-0,7 mm, sésseis; cálice $0,3-1,0 \times 0,3-0,4 \mathrm{~mm}$, campanulado, setoso, paleáceo, verde, glabro; corola 1,5-2,4 × 0,9-1,0 mm, campanulada, tetrâmera, branca, externamente puberulenta, lacínias eretas a ligeiramente encurvadas, tricomas simples e glandulares; androceu isostêmone, filetes 1,0-2,0 mm comp., livres, róseos, anteras oblongas, verde-amareladas; ovário $0,5-1,0 \mathrm{~mm}$ comp., séssil, oblongo, esverdeado, glabro, estilete 0,5-1,5 mm comp., glabro. Craspédios 2,0-3,7 × 0,5-1,2 cm, oblongos, marrom-amarelados, sésseis, cartáceos, plano-compressos, 35 articulados, ápice acuminado, base arredondada, estrigosos, tricomas simples; artículos quadrangulares; replo reto, viloso, com setas compridas e rígidas. Sementes 3,0-4,0 × 2,0-3,0 $\mathrm{mm}$, ovais, castanhas.

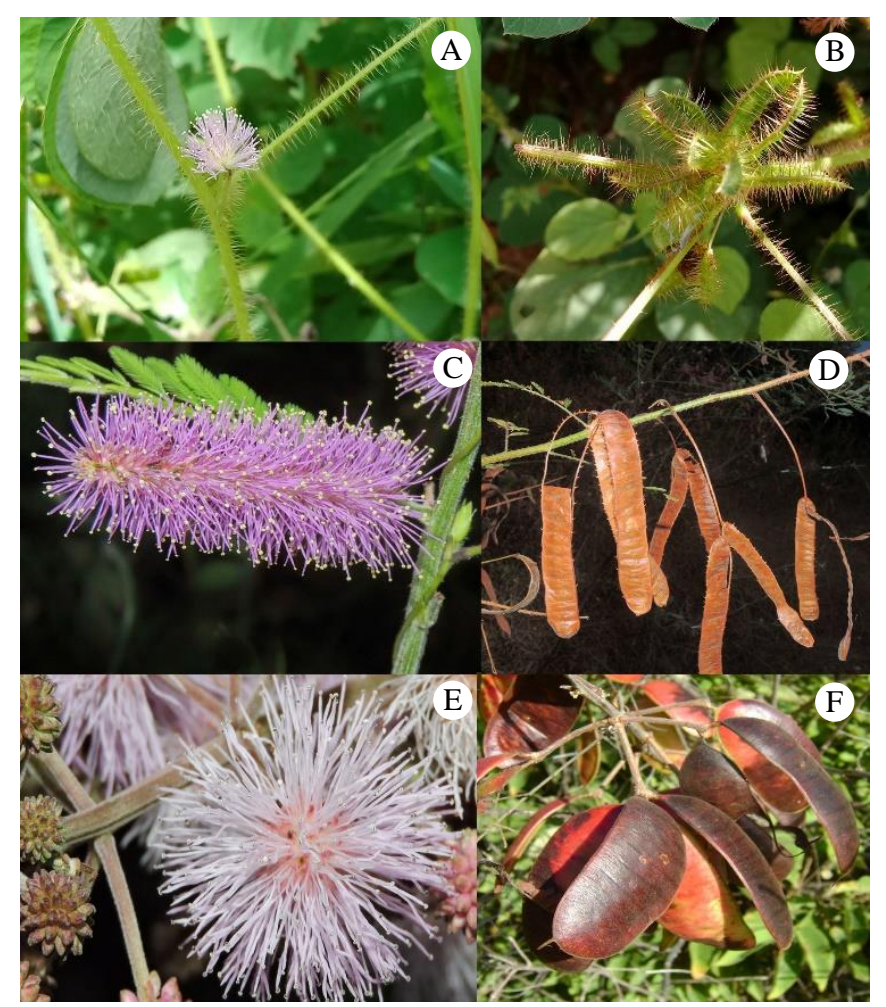

Figura 3. A-B. Mimosa debilis A. Glomérulo; B. Craspédios; C-D. Mimosa invisa C. Espiga; D. Craspédios; E-F. Mimosa paraibana E. Glomérulo; F. Craspédios.

Material examinado: Sítio Redondo, 04 ago 2019, fl., fr., E. E. Sousa 129 (JPB).

Distribuição geográfica: Exclusiva da América do Sul, ocorre na Venezuela, Guianas e no Brasil, em todas as regiões do país. Observada em áreas de Caatinga, Campo Rupestre, Cerrado, Floresta de Terra Firme, Floresta Estacional Semidecidual, Floresta Ombrófila e Restinga (Barneby, 1991; Tozzi et al., 2016; Flora do Brasil em construção, 2020). Coletada em Cachoeira dos Índios em serrotes, estando associada principalmente a componentes do extrato arbustivoarbóreo, como outras espécies da mesma família (Mimosa paraibana, M. tenuiflora, Senegalia polyphylla (DC.) Britton \& Rose, S. tenuifolia (L.) Britton \& Rose), além de membros de Bromeliaceae, Bignoniaceae, Cactaceae,
Cochlospermaceae, Chrysobalanaceae, Euphorbiaceae e Lamiaceae. Abelhas foram verificadas como visitantes florais.

Notas taxonômicas: Mimosa sensitiva pode ser confundida com Mimosa debilis por compartilharem folhas com 1 par de pinas, cada pina com apenas 4 foliólulos, sendo o foliólulo interno do par basal atrofiado. No entanto, $M$. sensitiva apresenta acúleos seriados, foliólulos falcados, flores com corola exclusivamente tetrâmera e cálice setoso (vs. acúleos internodais, foliólulos obovados, flores com corola tetrâmera ou pentâmera e cálice denteado em $M$. debilis). Floresce e frutifica na área de estudo em agosto.

\section{Mimosa tenuiflora (Wild.) Poir. Encycl. Suppl.1: 82.1810. (Figura 4C-D)}

Arvoretas ou arbustos, 2,0-5,0 m alt. Ramos marrons a vináceos, cilíndricos, aculeados, pubescentes, tricomas simples esbranquiçados e/ou glandulares enegrecidos. Acúleos 0,4-1,8 cm comp., retos, internodais, agudos, com base mamilar. Estípulas 1,7-3,4 ×0,1-0,2 mm, estreitamente triangulares, ciliadas, tricomas simples. Folhas pinadas, 3-7 pares de pinas, imparipinadas; pecíolos 7-9 $\mathrm{mm}$ comp., cilíndricos, puberulentos, tricomas simples e glandulares; raque 1,1-5,6 cm comp., cilíndrica, puberulenta, tricomas simples e glandulares; espículas interpinais subuladas; parafilídios cônicos; movimentos tigmonásticos ausentes; pinas 1,1-6,1 × 0,8-1,6 cm., oblongas; foliólulos 4-7 × 1,5 $\mathrm{mm}$, sésseis, oblongos, cartáceos, ápice arredondado, base oblíqua, margem discretamente ciliada, puberulentos, com pontuações glandulares na face abaxial, tricomas simples, nervação hifódroma. Espigas 5,1-7,6 $\times 0,9-1,5 \mathrm{~cm}$, cilíndricas, solitárias, axilares; pedúnculo 4,3-8,8 $\mathrm{mm}$ comp., cilíndrico, puberulento, tricomas simples e glandulares; brácteas 1-1,2 mm comp., obovadas a oblanceoladas, verdes, margens ciliadas, tricomas simples. Flores 2,3-4,1 × 1,1-1,4 mm, sésseis; cálice 0,8-0,9 × 0,40,7 mm, campanulado, 4-angulado por nervuras proeminentes e recurvadas, branco-esverdeado, puberulento, tricomas simples; corola 1,2-1,5 × 1-1,1 mm, campanulada, tetrâmera, branca, glabra, lacínios encurvados a ligeiramente reflexas; androceu diplostêmone, filetes 5-6,4 mm comp., livres, brancos; anteras oblongas, amarelas; ovário ca. 1,4 mm comp., séssil, oblongo, puberulento; estilete ca. $5,0 \mathrm{~mm}$ compr., glabro. Craspédios 2,3-5,4 × 5,3-7,8 mm, oblongos, marrons, estipitados, cartáceos, plano-corrugados, 3-6 articulados, ápice mucronado, base atenuada, puberulentos, tricomas simples e glandulares; estípite 2,7-5 mm comp., artículos quadrangulares, inflados na região das sementes; replo ligeiramente ondulado, puberulento, tricomas simples e glandulares. Sementes 3,9-4,5× 2,8-3,8 mm, ovoides, marrom-escuras.

Material examinado: Sítio Baixa Grande, 26 dez 2018, fr., E. E. Sousa 01 (JPB); 08 jul 2019, fl., fr., E. E. Sousa 119 (JPB); 31 jul 2019, fl., fr., E. E. Sousa 125 (JPB); 09 jan 2020, fl., E. E. Sousa 147 (JPB).

Distribuição geográfica: Mimosa tenuiflora é referida para Venezuela, Colômbia, México, Honduras, El Salvador e Brasil. No Brasil, forma grandes populações em áreas susceptíveis a secas periódicas, com ocorrência na região Nordeste, estendendo-se ao estado de Minas Gerais e 
também cultivada no Pará (Barneby, 1991; Santos-Silva et al., 2015, Flora do Brasil em Construção, 2020). A espécie foi coletada, em Cachoeira dos Índios, em áreas mais abertas, onde estava associada a vários componentes do extrato predominante, o herbáceo, como táxons de outros gêneros de Fabaceae (Centrosema, Chamaecrista, Crotalaria, Desmodium, Indigofera, Senna), e membros de Amaranthaceae, Asteraceae, Euphorbiaceae, Malvaceae, Poaceae e Rubiaceae. Das espécies arbustivas ou arbóreas, $M$. tenuiflora foi observada como a mais frequente e também foram vistos, esparsamente, outros representantes de Fabaceae (Bauhinia cheilanta (Bong.) Steud., Libidibia ferrea (Mart. ex Tul.) L. P. Queiroz, Luetzelburgia sp., M. arenosa), bem como de Anacardiaceae, Bignoniaceae, Cactaceae, Combretaceae, Euphorbiaceae). Foram visualizadas abelhas como visitantes florais.

Notas taxonômicas: Mimosa tenuiflora é facilmente distinguida das demais espécies estudadas pelos ramos marrons a vináceos, pontuações glandulares escuras na face abaxial dos foliólulos, cálice 4-angulado com costelas proeminentes e encurvadas, ovário puberulento e craspédios plano-corrugados com artículos inflados na região das sementes. Floresce em janeiro e julho e frutifica nos meses de julho e dezembro. Conhecida popularmente como jurema preta.

9. Mimosa ursina Mart. Flora 21: 56. 1838. (Figura 4E-F) Subarbusto ereto, ca. $30 \mathrm{~cm}$ alt. Ramos cilíndricos, verdes, aculeados, híspidos, tricomas simples. Acúleos 0,2-0,4 cm comp., retos, longos, frágeis, infranodais. Estípulas $0,3-0,7 \times$ $0,1 \mathrm{~cm}$, lanceoladas, verdes, ciliadas, tricomas simples. Folhas palmadas, 1 par de pinas; pecíolos 1,3-4,0 cm comp., cilíndricos, híspidos; raque ausente; movimentos tigmonásticos presentes; espículas interpinais presentes; parafilídios subulados; pinas 1,3-2,0 × 0,7-2,0 cm, oblongas, articuladas por tecido contrátil em cada par de foliólulos 4-5 pares; foliólulos $0,9-1,2 \times 0,4-0,5 \mathrm{~cm}$, oblongos, verdes, bicolores, glaucos, ápice arredondado a apiculado, margem ciliada, base oblíqua, ambas as faces glabras, tricomas simples, nervação actinódroma. Glomérulos 2,0-3,0 $\mathrm{mm}$ diâm., globosos, solitários, axilares; pedúnculos 1,0-3,2 cm comp., cilíndricos, híspidos, tricomas simples; brácteas $1,0 \times 0,3-0,5$ mm comp., oblanceoladas, margens ciliadas, verdes, tricomas simples. Flores 2,0-4,0 × 0,5-0,8 mm, sésseis; cálice 0,4-0,5 $\times 0,4-0,5 \mathrm{~mm}$, campanulado, verde, glabro; corola 1,2-1,3 $\times$ $0,8 \mathrm{~mm}$, campanulada, tetrâmera, lacínias eretas, rosa, glabra; androceu isostêmone, filetes 1,5-2,0 mm comp., livres, róseos, anteras oblongas, amarelas; ovário 0,5-0,8 $\mathrm{mm}$ comp., oblongo, séssil, puberulento, estilete 1,0-2,0 mm comp, glabro. Craspédios 1,2-2,0 × 0,4-0,7 cm, oblongos, 2-3 articulados, sésseis, marrons, planos, cartáceos, ápice mucronado, base arredondada, armados com espinhos cônicos, vilosos, tricomas simples e glandulares; artículos quadrangulares; replo sinuoso, híspido, tricomas setosos. Sementes 4,0-5,0 × 3,0-4,0 mm, ovais, castanhas.

Material examinado: Sítio São Joaquim, 04 fev 2019, fl., fr., E. E. Sousa 26, 27, 28, 29, 30, 31, 32 (JPB); Sítio Baixa Grande, 21 abr 2019, fr., E. E. Sousa 96, 97, 98 (JPB).

Distribuição geográfica: Nativa do Brasil, com registros até o momento principalmente no Nordeste (BA, CE, MA, PE, PI,
$\mathrm{RN}$ ), em vegetações de Caatinga e Cerrado. Na Caatinga, cresce sobre solos arenosos a altitudes de 120 a 400 metros (Queiroz, 2009; Flora do Brasil em construção, 2020). É aqui apontada como nova ocorrência para o estado da Paraíba, coletada exclusivamente em ambientes serranos de Cachoeira dos Índios. Nestas áreas do município, a espécie estava associada a componentes do extrato herbáceo e subarbustivo típico de Caatinga, como outros representantes de Fabaceae (Chamaecrista pilosa var. Luxurians (Benth.) H. S. Irwin \& Barneby, Centrosema brasilianum (L.) Benth., Macroptilium martii Benth.), além de táxons de Poaceae, Euphorbiaceae, Asteraceae e Malvaceae. Visitantes florais não foram vistos.

Notas taxonômicas: Mimosa ursina pode ser diagnosticada pelas folhas palmadas com apenas um par de pina, característica compartilhada com $M$. debilis e $M$. sensitiva, sendo M. ursina com 4-5 pares de foliólulos (vs. 2 pares de foliólulos em $M$. debilis e $M$. sensitiva). Floresce em fevereiro e frutifica de fevereiro a abril.

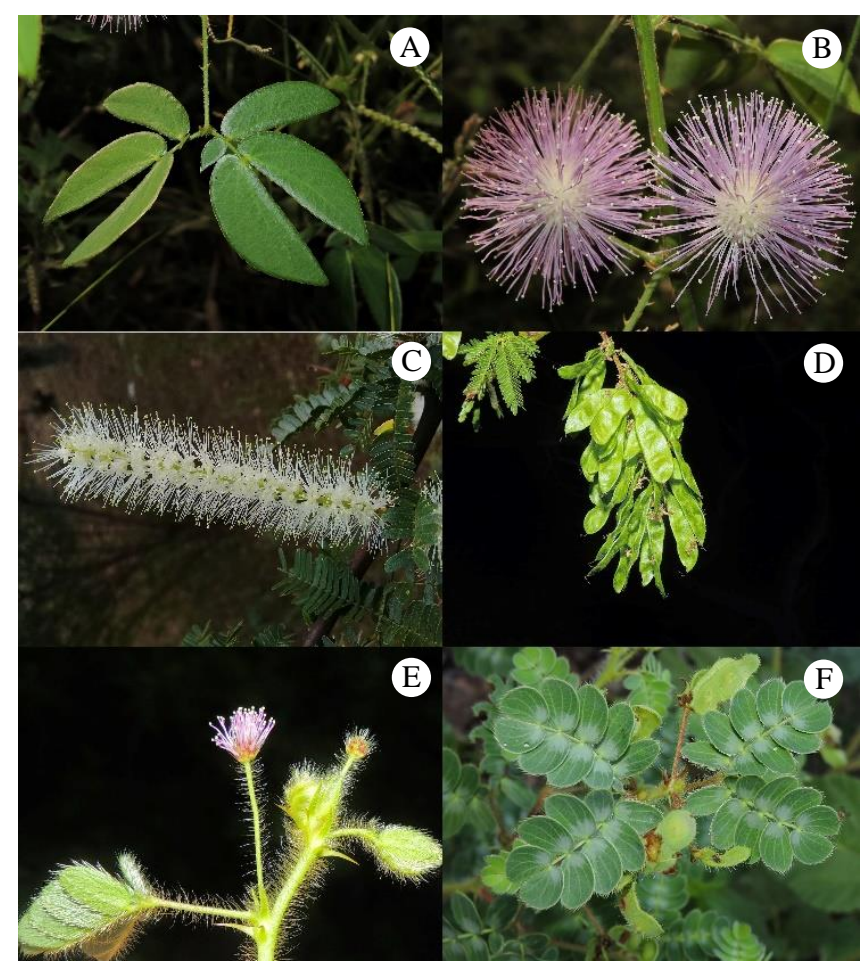

Figura 4. A-B. Mimosa sensitiva A. folha 1 par de pinas; B. Glomérulos; C-D. Mimosa tenuiflora C. Espiga; D. Craspédios; E-F. Mimosa ursina E. Glomérulo; F. Folhas e Craspédios.

\section{Conclusões}

A diversidade e a riqueza de Mimosa em Cachoeira dos Índios são consideradas altas, uma vez que, o número de espécies do gênero catalogadas no município foi aproximado ou maior, quando comparado aos resultados encontrados em áreas de Caatinga correlatas e também correspondeu a mais da metade dos táxons deste grupo já registrados para o estado da Paraíba, alguns deles formando densas populações nos pontos onde foram coletados. Ademais, destacam-se os novos registros na Paraíba e táxons endêmicos do Nordeste brasileiro elencados, ampliando assim, os dados da 
distribuição geográfica do grupo, bem como, complementações taxonômicas para futuros estudos das Fabaceae na região.

\section{Referências}

Barneby, R. C. (1991). Sensitivae censitae: a description of the genus Mimosa Linnaeus (Mimosaceae) in the New World. (vol. 65, pp. 835). New York: Memoirs of the New York Botanical Garden.

BFG. (2015). Growing knowledge: an overview of Seed Plant diversity in Brazil. Rodriguésia, 66(4), 1085-1113. doi: 10.1590/21757860201566411.

Burkart, A. (1979). Leguminosas: Mimosoideas. In: Reitz, P.R. Flora ilustrada Catarinense, Part. 1. p. 49-83.

Döhler, T. L.; \& Pina, W. C. (2017). Abelhas (Hymenoptera: Apoidea) visitantes florais do sabiá (Mimosa caesalpiniifolia Benth.) em Teixeira de Freitas, Bahia, Brasil. Scientia Plena, 13(8), 1-7. doi: 10.14808/sci.plena.2017.088001.

Dourado, D. A. O., Conceição, A. S., \& Santos-Silva, J. (2013). O gênero Mimosa L. (Leguminosae: Mimosoideae) na APA Serra Branca/Raso da Catarina, Bahia, Brasil. Biota Neotropica, 13(4), 225-240. Recuperado de http://www.biotaneotropica.org.br/v13n4/pt/abstract?inventory+bn01713 042013.

Embrapa Solos. (2018). Sistema Brasileiro de Classificação de Solos (5ª ed.). Brasília, DF: Embrapa.

Farias, R. C.; Lacerda, A. V.; Gomes, A. C.; Barbosa, F. M.; \& Dornelas C. S. (2017). M. Riqueza florística em uma área ciliar de Caatinga no Cariri Ocidental da Paraíba, Brasil. Revista Brasileira de Gestão Ambiental e Sustentabilidade, 4(7), 109-118. doi: 10.21438/rbgas.040711.

Ferreira, P. S. M., Trovão, D. M. B. M., \& Melo, J. I. M. (2015). Leguminosae na APA do Cariri, Estado da Paraíba, Brasil. Hoehnea, 42(3), 531-547. doi: 10.1590/2236-8906-04/2015.

Flora do Brasil 2020 em construção. Jardim Botânico do Rio de Janeiro. Disponível em http://floradobrasil.jbrj.gov.br/reflora/floradobrasil/FB115

Gadelha-Neto P.C., Lima J.R., Barbosa M.R.V., Barbosa M.A., Menezes M., Pôrto K.C., Wartchow F. \& Gibertoni T.B. (2013). Manual de Procedimentos para Herbários. (pp. 53). Recife. Editora Universitária da UFPE.

Gonçalves, E.G., \& Lorenzi, H. J. (2011). Morfologia vegetal: organografia e dicionário ilustrado de morfologia das plantas vasculares ( $2^{\mathrm{a}}$. ed. pp. 512). São Paulo: Instituto Plantarum de Estudos da Flora.

Instituto Brasileiro de Geografia e Estatística. (2018). Área territorial brasileira. Rio de Janeiro: IBGE. Recuperado de https://cidades.ibge.gov.br/brasil/pb/cachoeira-dosindios/pesquisa/33/29167? indicador $=29171 \&$ ano $=2018$.

LPWG. (2017). A new subfamily classification of the Leguminosae based on a taxonomically comprehensive phylogeny. Taxon, 66(1), 44-77. doi: 10.12705/661.3.

Maia-Silva, C., Silva, C. I., Hrncir, M., Queiroz, R. T., \& Imperatriz-Fonseca, V. L. (2012). Guia de plantas visitadas por abelhas na Caatinga. (pp; 191). Fortaleza: Editora Fundação Brasil Cidadão.

Mattos, C. M. J., Silva, W. L. S., Carvalho, C. S., Lima, A. N., Faria, S. M. \& Lima, H. C. (2018). Flora das cangas da serra dos Carajás, Pará, Brasil: Leguminosae. Rodriguésia, 69(3), 1147-1220. doi: 10.1590/21757860201869323

Matos, S. S., Melo, A. L., \& Santos-Silva. (2019). Clado Mimosoideae (Leguminosae-Caesalpinioideae) no Parque Estadual Mata da Pimenteira, Semiárido de Pernambuco, Brasil. Rodriguésia, 70(01902017), 1-17. doi: 10.1590/2175-7860201970007.

Queiroz, L. P. (2009). Leguminosas da Caatinga. (pp. 913). Feira de Santana: Universidade Federal de Feira de Santana/ Royal Botanic Gardens Kew / Associação Plantas do Nordeste.

Rodrigues, E. M. (2018). Levantamento taxonômico de Fabaceae Lindl. em um afloramento granítico do Semiárido Brasileiro (Dissertação de Mestrado). Universidade Estadual de Paraíba, Campina Grande, Paraíba.

Santos-Silva, J.; Simon, M. F. \& Tozzi, A. M. G. A. (2015). Revisão taxonômica das espécies de Mimosa ser. Leiocarpae sensu lato (Leguminosae - Mimosoideae). Rodriguésia, 66(1), 095-154. doi: $10.1590 / 2175-7860201566107$.
Silva, J. S. \& Sales, M. F. (2007). O gênero Mimosa (LeguminosaeMimosoideae) na microrregião do Vale do Ipanema, Pernambuco. Rodriguésia, 59(3), 435-448. doi: 10.1590/2175-7860200859302.

Silva, S. A. L. \& Melo, J. I. M. (2013). A família Leguminosae Juss. em dois afloramentos rochosos no município de Puxinanã, Paraíba. Biotemas, 26(4), 23-43. doi: 10.5007/2175-7925.2013v26n4p23.

Simon, M. F., Grether, R., Queiroz, L. P., Särkinen, T. E., Dutra, V. F. \& Hughes, C. E. (2011). The evolutionary history of Mimosa (Leguminosae): toward a phylogeny of the sensitive plants. American Journal of Botany, 98(7), 1201-1221. doi: 10.3732/ajb.1000520.

Souza, V. C., Flores, T. B., \& Lorenzi, H. (2013). Introdução à Botânica: morfologia. (pp. 223) São Paulo: Instituto Plantarum de Estudos da Flora.

Tozzi, A. M. G. A., Melhem, T. S., Forero, E., Fortuna-Perez, A. P., Wanderley, M. G. L., Martins, S. E., Romanini, R. P., Pirani, J. R., Melo, M. M. R. F., Kirizawa, M., Yano, O. \& Cordeiro, I. (2016). Flora fanerogâmica do estado de São Paulo online (vol. 8. pp. 451). São Paulo: Instituto de Botânica,.

Vidal, W. N.; Vidal, M. R. R. (2003). Botânica Organografia: Quadros Sinóticos Ilustrados de Fanerógamos (4.ed. pp. 124). Viçosa: Universidade Federal de Viçosa,

\section{Licença Creative Commons CC BY 4.0}

Este artigo foi publicado com acesso aberto para distribuíção sob os termos do Licença de Atribuição Creative Commons, que permite uso irrestrito, distribuição, e reprodução em qualquer meio, desde que o trabalho original seja devidamente citado. 